\section{Sorafenib improves survival of FLT3-mutated acute myeloid leukemia in relapse after allogeneic stem cell transplantation: a report of the EBMT Acute Leukemia Working Party}

The prognosis of acute myeloid leukemia (AML) with FMS-like tyrosine kinase 3 internal tandem duplication (FLT3-ITD) is generally poor and these patients are referred to allogeneic stem cell transplantation (allo-SCT) in first complete remission (CR). ${ }^{1}$ However, long-term survival remains poor because of early relapse and lack of response to further treatment. ${ }^{2}$ Furthermore, relapse after allo-SCT has a dismal outcome with a 1-year survival below $20 \%$.

FLT3 tyrosine kinase inhibitors (TKI) were tested in
FLT3-ITD AML. ${ }^{3}$ Midostaurin improves overall survival (OS) when combined with chemotherapy, which led to its approval. ${ }^{4}$ Because of its availability, sorafenib has been studied in various settings in FLT3-ITD AML, including first-line therapy, post-transplant maintenance therapy, or treatment of relapse, either alone or combined with chemotherapy or hypomethylating agents. ${ }^{3,5-10}$ Gilteritinib was recently approved for relapsed/refractory FLT3-ITD AML and is currently being tested (BMT-CTN 1506; clinicaltrials.gov identifer: 02997202) as post-transplant maintenance. Conflicting results were reported on the use of sorafenib or other FLT3 inhibitors, either alone or combined with donor lymphocyte infusion (DLI), chemotherapy, or azacytidine, for patients in relapse after allo-SCT. $5,9,11-13$

Table 1. Patients' and transplant characteristics.

\begin{tabular}{|c|c|c|c|}
\hline & $\begin{array}{l}\text { Control } \\
\text { N }(\%)\end{array}$ & $\begin{array}{c}\text { Sorafentb } \\
\text { N }(\%)\end{array}$ & $P$ \\
\hline Number of patients & 118 & 34 & \\
\hline Female & $59(50)$ & $13(38)$ & 0.226 \\
\hline Age at transplant; median (range) & $51(19-75)$ & $48(19-69)$ & 0.792 \\
\hline Year of transplant (range) & $2012(2010-2015)$ & $2013(2010-2015)$ & 0.05 \\
\hline Time from transplant to relapse; median; months (range) & $3.7(0.6-58.3)$ & $2.8(0.4-41.4)$ & 0.169 \\
\hline $\begin{array}{l}\text { Molecular profile } \\
\text { NPM1 }\end{array}$ & $41(40)$ & $14(41)$ & 0.888 \\
\hline $\begin{array}{l}\text { Cytogenetics } \\
\text { Favorable } \\
\text { Intermediate } \\
\text { Adverse }\end{array}$ & $\begin{array}{c}4(3) \\
93(79) \\
19(16)\end{array}$ & $\begin{array}{c}0(0) \\
28(82) \\
5(15)\end{array}$ & 0.698 \\
\hline N. of inductions; median (range) & $1(1-8)$ & $1.5(1-3)$ & 0.939 \\
\hline CR after induction 1 & $74(66)$ & $19(59)$ & 0.485 \\
\hline Consolidation given & $85(72)$ & $20(61)$ & 0.207 \\
\hline Follow up after relapse for alive patients; months (range) & $19.74(4.3-68.23)$ & $22.69(3.84-67.77)$ & 0.49 \\
\hline $\begin{array}{l}\text { Status at transplant } \\
\text { CR1 } \\
\text { CR2 } \\
\text { Active disease }\end{array}$ & $\begin{array}{l}72(61) \\
13(11) \\
33(28)\end{array}$ & $\begin{array}{l}18(53) \\
4(12) \\
12(35)\end{array}$ & 0.676 \\
\hline $\begin{array}{l}\text { Donor type } \\
\text { Matched Related Donor } \\
\text { Matched Unrelated Donor } \\
\text { Haploidentical Donor }\end{array}$ & $\begin{array}{l}50(42) \\
59(50) \\
9(8)\end{array}$ & $\begin{array}{l}23(68) \\
8(24) \\
3(9)\end{array}$ & 0.021 \\
\hline $\begin{array}{l}\text { Conditioning } \\
\text { Myeloablative } \\
\text { Reduced Intensity } \\
\text { In vivo TCD }\end{array}$ & $\begin{array}{l}56(47) \\
62(53) \\
67(57)\end{array}$ & $\begin{array}{l}23(68) \\
11(32) \\
18(53)\end{array}$ & $\begin{array}{l}0.038 \\
0.691\end{array}$ \\
\hline $\begin{array}{l}\text { Stem cell source } \\
\text { BM } \\
\text { PBSC }\end{array}$ & $\begin{array}{l}19(16) \\
99(84)\end{array}$ & $\begin{array}{c}4(12) \\
30(88)\end{array}$ & 0.534 \\
\hline $\begin{array}{l}\text { Minimal residual disease (MRD) } \\
\text { MRD negative at transplant } \\
\text { MRD positive at transplant }\end{array}$ & $\begin{array}{l}68(58) \\
50(42)\end{array}$ & $\begin{array}{l}11(32) \\
23(68)\end{array}$ & 0.009 \\
\hline Patient CMV negative & $52(44)$ & $7(21)$ & 0.013 \\
\hline Donor CMV negative & $52(44)$ & $13(38)$ & 0.52 \\
\hline $\begin{array}{l}\text { GvHD } \\
\text { Acute GvHD grade II-IV } \\
\text { Chronic GvHD before relapse }\end{array}$ & $\begin{array}{l}32(28) \\
18(16) \\
\end{array}$ & $\begin{array}{l}9(28) \\
4(12)\end{array}$ & $\begin{array}{l}0.952 \\
0.563 \\
\end{array}$ \\
\hline
\end{tabular}

N: number; CR: complete remission;TCD:T-cell depletion; BM: bone marrow; PBSC: peripheral blood stem cell; MRD: minimal residual disease; CMV: cytomegalovirus; GvHD: graft-versus-host disease. 


\section{os}

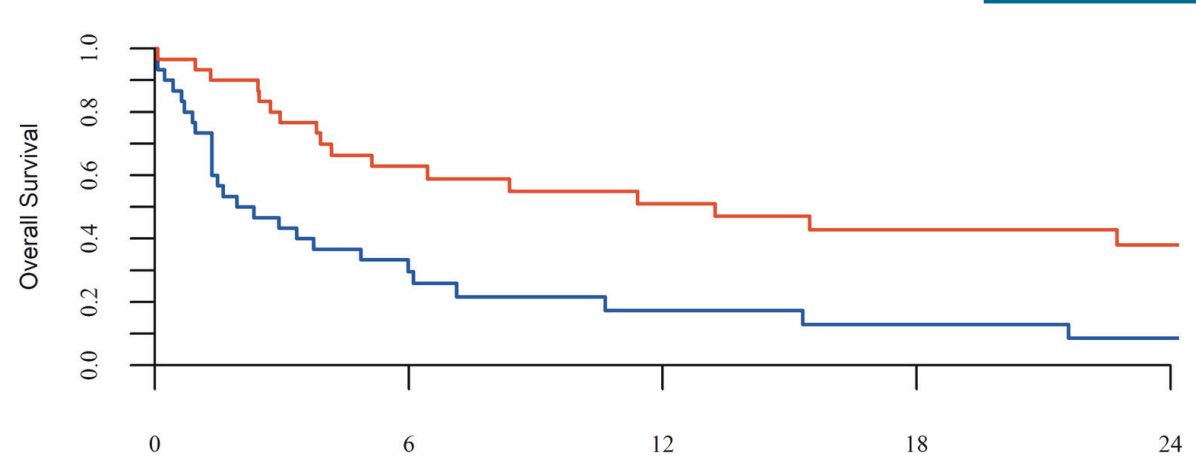

Figure 1. Overall survival (OS) (landmark analysis from relapse after allogeneic stem cell transplantation).

Time from relapse (months)

number of at-risk patients

$\begin{array}{ccc}4 & 3 & 2 \\ 13 & 10 & 7\end{array}$

4

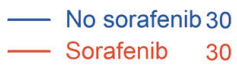

30
8
18 having survived at least as long as time elapsed from relapse to first infusion of sorafenib for each case, in order to avoid immortal time bias. We randomly selected one control if a case had multiple potential matches. In order to take into account correlation between case and control, comparison of case and controls was performed using Cox including a cluster term for each pair and adjusted for time interval from transplant to relapse. All tests were two-sided. The type- 1 error rate was fixed at 0.05 for determination of factors associated with time-toevent outcomes. All analyses were performed using $R$ version 3.4.1 (R Core Team, Vienna, Austria).

Altogether, 152 patients met the eligibility criteria for this study. The median time from allo-SCT to relapse was three months (range 0.4-58) and the median follow up after relapse of alive patients was 22 months (range 4$68)$. Thirty-four patients $(22 \%)$ received sorafenib as salvage therapy for relapse/progression after allo-SCT (sorafenib group). These patients were compared with 118 patients who did not receive sorafenib salvage after allo-SCT (control group). Comparisons of patients' and transplant characteristics between the two groups are listed in Table 1. The median age at allo-SCT was 48 (range 19-69) years in the sorafenib group versus 51 (range 19-75) years in the control group (NS). Patients in the sorafenib group were less likely to be CMV negative or MRD negative, but more likely to have received a transplant from a matched related donor and a myeloablative conditioning. The two groups were comparable in terms of other patient, disease and transplant characteristics. Overall, $33 \%$ of patients in the sorafenib group received DLI versus $17 \%$ in the control group (NS). A second allo-SCT was performed in $13 \%$ and $15 \%$ of patients, respectively (NS).

The median time from relapse to any type of therapy was six days (range 1-34) in the sorafenib group versus eight days (range 1-245) in the control group. Sorafenib was initiated after a median of 13 days (range 1-128) from relapse at the dose of $800 \mathrm{mg} /$ day in 21 patients $(62 \%), 400 \mathrm{mg} /$ day in $12(35 \%)$, and $200 \mathrm{mg} /$ day in one patient (3\%), for a median duration of 79 days (range 1 1670). The sorafenib dose was modified in $35 \%$ of patients, mostly because of hematologic toxicity. In the 
sorafenib group, $23(68 \%)$ patients received sorafenib as part of the first treatment for relapse, and 11 received it after salvage chemotherapy. Sorafenib induced CR in 10 $(39 \%)$ of 26 patients with available data on response.

In multivariate Cox analysis (Table 2), sorafenib given as salvage for relapse as a time dependent variable significantly improved OS $[\mathrm{HR}=0.44(0.26-0.75) ; P=0.001]$. However, older age [per 10 years, $\mathrm{HR}=1.2$ (1.01-1.43); $P=0.04]$, active disease at transplant $[\mathrm{HR}=2.4(1.49-3.84)$; $P=0.001]$, and reduced intensity conditioning $[\mathrm{HR}=1.76$ (1.14-2.73); $P=0.01]$ adversely affected OS. Time from transplant to relapse had no significant impact on OS $[\mathrm{HR}=0.98$ (0.96-1.01); $P=0.17]$.

Thirty patients in the sorafenib group were matched with 30 controls. Patients', disease and transplant characteristics of both groups are presented in Online Supplementary Tables S1 and S2. One and 2-year OS were, $51 \%$ and $38 \%$ for patients in the sorafenib group versus $17 \%$ and $9 \%$ for controls, respectively $[\mathrm{HR}=0.28(0.15-$ 0.53); $P=0.0001$ ] (Figure 1).

In this study, we compared outcomes of 34 patients with FLT3-ITD AML who relapsed or progressed after allo-SCT and received sorafenib as salvage therapy to those of 124 similar patients who did not receive sorafenib salvage. In this challenging setting, sorafenib treatment resulted in a CR rate of $39 \%$. The one- and 2year OS from relapse post allo-SCT, for patients in the sorafenib group, were encouraging $(51 \%$ and $38 \%$, respectively), and significantly better than those of the control group who did not receive sorafenib $(17 \%$ and

Table 2. Multivariate analysis for overall survival.

\begin{tabular}{lc} 
& HR \\
& $(95 \% \mathrm{Cl})$ \\
& $\boldsymbol{P}$ \\
Sorafenib given for relapse (time dependent) & $0.44(0.26-0.75)$ \\
& $P=0.002$ \\
Age at allo-SCT (per 10 years) & $1.2(1.01-1.43)$ \\
& $P=0.04$ \\
\hline CR1 (reference) & \\
CR2 & $1.52(0.81-2.85)$ \\
& $P=0.19$ \\
\hline Active disease & $2.4(1.49-3.84)$ \\
& $P<0.001$
\end{tabular}

\begin{tabular}{lc} 
Matched related donor (reference) & \\
\hline Matched unrelated donor & $1.42(0.89-2.25)$ \\
& $P=0.14$ \\
Haploidentical & $0.68(0.33-1.42)$ \\
& $P=0.3$ \\
\hline RIC vs. MAC & $1.76(1.14-2.73)$ \\
NPM1 positive & $P=0.01$ \\
& $1.34(0.86-2.09)$ \\
Time from allo-SCT to relapse (per month) & $P=0.19$ \\
& $0.98(0.96-1.01)$ \\
& $P=0.17$
\end{tabular}

\begin{tabular}{lc} 
Patient CMV positive & $1.58(1-2.5)$ \\
& $P=0.051$ \\
\hline Donor CMV positive & $1.21(0.79-1.85)$ \\
& $P=0.39$ \\
\hline
\end{tabular}

HR: Hazard Ratios; CI: Confidence Intervals; allo-SCT: allogeneic stem cell transplantation;CR1:first complete remission; CR2: second complete remission; RIC: reduced intensity conditioning; MAC: myeloablative conditioning; CMV: cytomegalovirus.
$9 \%$, respectively; $P=0.0001)$.

Treatment of patients with FLT3-ITD AML who relapse or progress after allo-SCT remains a real challenge and an unmet medical need. Chemotherapy alone or combined with DLI is rarely effective in the long term. ${ }^{14}$ A second allo-SCT can be proposed to a small percentage of patients. Currently, the most attractive treatment options for patients with FLT3-ITD AML failing allo-SCT are TKI with or without DLI.

Conflicting findings were previously reported on the efficacy of sorafenib salvage in FLT3-ITD AML relapsing after allo-SCT. ${ }^{12,15}$ A recent report showed that six of 29 patients with FLT3-ITD AML, in relapse after allo-SCT and treated with sorafenib monotherapy, were alive after a median follow up of 7.5 years. ${ }^{11}$ However, Sharma et al. ${ }^{13}$ reported that none of 16 patients treated with sorafenib for relapse after allo-SCT, was still alive at one year. Besides the higher number of patients in our study, one important difference with the other reported series is our inclusion of a large control group and performance of a pair-match analysis.

In addition to the direct anti-leukemia effect of sorafenib, a possible synergistic effect with alloreactive donor $\mathrm{T}$ cells in facilitating long-term disease control has been suggested. ${ }^{15}$ Interestingly, in our cohort, DLI was administered to $33 \%$ of the patients in the sorafenib group as compared to $17 \%$ of patients in the control group. DLI may therefore synergize with sorafenib to achieve sustained disease control. Nevertheless, we did not observe any increase in de novo GvHD in our sorafenib group, despite the higher rate of DLI in this group.

While we cannot recommend a dose of sorafenib for treatment of relapse after allo-SCT, our data indicate that the standard daily dose of $800 \mathrm{mg}$ in two divided doses is safe in this setting, although dose adjustments were frequently needed.

In conclusion, sorafenib is a safe and effective salvage therapy for patients with FLT3-ITD AML relapsing or progressing after allo-SCT, leading to a significant improvement in OS.

Ali Bazarbachi, 1,2 Myriam Labopin, ${ }^{3,4,5}$ Giorgia Battipaglia, ${ }^{4,6}$ Azedine Djabali, ${ }^{3,4}$ Jakob Passweg, $^{7}$ Gerard Socié, ${ }^{8}$

Edouard Forcade, 9 Didier Blaise, ${ }^{10}$ Patrice Chevallier, ${ }^{11}$ Corentin Orvain, ${ }^{12}$ Jan J. Cornelissen, ${ }^{13}$ William Arcese,,$^{14}$ Sylvain Chantepie, ${ }^{15}$ Khowla Hashaishi, Jean El Cheikh, Michael Medinger, Jordi Esteve, ${ }^{3,16}$ Arnon Nagler, ${ }^{3,17^{*}}$ and Mohamad Mohty ${ }^{3,4,5^{*}}$

*AN and MM contributed equally to this work.

${ }^{1}$ Bone Marrow Transplantation Program, Department of Internal Medicine, American University of Beirut Medical Center, Beirut, Lebanon; ${ }^{2}$ Department of Cell Biology, Anatomy and Physiological Sciences, American University of Beirut, Beirut, Lebanon;

${ }^{3}$ Acute Leukemia Working Party of EBMT, Paris, France; ${ }^{4}$ Hematology Department, Hôpital Saint Antoine, Service d'Hématologie et Thérapie Cellulaire, Paris, France; 'Hôpital Saint Antoine, Université Pierre and Marie Curie, INSERM, UMRs 938, Paris, France; ${ }^{6}$ Hematology Department, Federico II University of Naples, Naples, Italy;

${ }^{7}$ University Hospital, Hematology, Basel, Switzerland; ${ }^{8}$ Hôpital Saint Louis, Department of Hematology - BMT, Paris, France;

${ }^{9} \mathrm{CHU}$ Bordeaux Hôpital Haut-leveque, Pessac, France; ${ }^{10}$ Programme de Transplantation and Therapie Cellulaire, Centre de Recherche en Cancérologie de Marseille, Institut Paoli Calmettes, Marseille, France; ${ }^{11} \mathrm{CHU}$ Nantes, Department D'Hematologie, Nantes, France; ${ }^{12} \mathrm{CHRU}$, Service des Maladies du Sang, Angers, France; ${ }^{13}$ Department of Hematology, Rotterdam, the Netherlands; ${ }^{14}$ Tor Vergata University of Rome, Stem Cell Transplant Unit, Polidinico Universitario Tor Vergata, Rome, Italy; ${ }^{15} \mathrm{CHU} C A E N$, Institut 
d'Hématologie de Basse-Normandie, Caen, France; ${ }^{16}$ Hematology Department, IDIBAPS, Hospital Clinic, Barcelona, Spain and ${ }^{17}$ Chaim Sheba Medical Center, Tel-Hashomer, Israel

Acknowledgments: participating centers (center, city) by decreasing number of patients enrolled in the study: University Hospital, Hematology, Basel; Hopital St. Louis, Department of Hematology BMT, Paris; CHU Bordeaux, Hôpital Haut-Leveque, Pessac; Programme de Transplantation and Therapie Cellulaire, Centre de Recherche en Cancérologie de Marseille, Institut Paoli Calmettes, Marseille; CHU Nantes, Department D'Hematologie, Nantes; CHRU, Service des Maladies du Sang, Angers; Hopital Saint Antoine, Department of Hematology, Paris; Erasmus MC Cancer Institute, University Medical Center Rotterdam, Department of Hematology, Rotterdam; Tor Vergata" University of Rome, Stem Cell Transplant Unit, Policlinico Universitario Tor Vergata, Rome; CHU CAEN, Institut d'Hématologie de Basse-Normandie, Caen; Turku University Hospital, TD7 (Stem Cell Transplant Unit), Turku; Cliniques Universitaires St. Luc, Department of Haematology, Brussels; Klinikum Grosshadern, Med. Klinik III, Munich; Techniciens dEtude Clinique Suivi de Patients Greffes, Nouvel Hopital Civil, Strasbourg; University Hospital Gasthuisberg, Department of Hematology, Leuven; University Hospital, Department of Bone Marrow Transplantation, Essen; Sheffield Teaching Hospitals NHS Trust, South Yorkshire Region (Adult) BMT Programme, Royal Hallamshire Hospital, Sheffield; Hospital Clinic, Institute of Hematology and Oncology, Department of Hematology, Barcelona; Gazi University Faculty of Medicine, Hematology, Ankara; S.S.C.V.D Trapianto di Cellule Staminali, A.O.U Citta della Salute e della Scienza di Torino, Torino; Nijmegen Medical Centre, Department of Hematology, Nijmegen; Ospedale Civile, Dipartimento di Ematologia, Medicina Trasfusionale e Biotecnologie, Pescara; Hopital Bretonneau, Service dOncologie Médicale, Tours; Istituto Clinico Humanitas, Transplantation Unit, Department of Oncology and Haematology, Milano; Department of Internal Medicine, American University of Beirut Medical Center, Beirut; George Papanicolaou General Hospital, Haematology Department / BMT Unit, Thessaloniki; Charles University Hospital, Department of Hematology/Oncology, Pilsen; Florence Nightingale Sisli Hospital, Hematopoietic SCT Unit, Abide - i Hurrivet Cad. 164 Sisli, Istanbul; Tel Aviv Sourasky Medical Center, Blood and Bone Marrow Transplantation, Tel Aviv; Leiden University Hospital, BMT Centre Leiden, Leiden; Western General Hospital, Department of Haematology, Edinburgh; Hannover Medical School, Department of Haematology, Hemostasis, Oncology, and Stem Cell Transplantation, Hannover; Universitaetsklinikum Goettingen, Abteilung Hämatologie und Onkologie, Goettingen; Institute of Hematology and Transfusion Medicine, Warsaw; University of Liege, Department of Hematology, CHU Sart-Tilman, Liege.

Correspondence: ALIBAZARBACHI - bazarbac@aub.edu.lb doi:10.3324/haematol.2018.211615

Information on authorship, contributions, and financial \& other disclosures was provided by the authors and is available with the online version of this article at www. haematologica.org.

\section{References}

1. Bornhauser $M$, Illmer $T$, Schaich $M$, et al. Improved outcome after stem-cell transplantation in FLT3/ITD-positive AML. Blood. 2007;109(5):2264-2265.

2. Schmid C, Labopin M, Socie G, et al. Outcome of patients with distinct molecular genotypes and cytogenetically normal AML after allogeneic transplantation. Blood. 2015;126(17):2062-2069.

3. Antar A, Otrock ZK, El-Cheikh J, et al. Inhibition of FLT3 in AML: a focus on sorafenib. Bone Marrow Transplant. 2017;52(3):344-351.

4. Stone RM, Mandrekar SJ, Sanford BL, et al. Midostaurin plus Chemotherapy for Acute Myeloid Leukemia with a FLT3 Mutation. N Engl J Med. 2017;377(5):454-464.

5. Borthakur G, Kantarjian H, Ravandi F, et al. Phase I study of sorafenib in patients with refractory or relapsed acute leukemias. Haematologica. 2011;96(1):62-68.

6. Chen YB, Li S, Lane AA, et al. Phase I trial of maintenance sorafenib after allogeneic hematopoietic stem cell transplantation for fms-like tyrosine kinase 3 internal tandem duplication acute myeloid leukemia. Biol Blood Marrow Transplant. 2014;20(12):2042-2048.

7. Brunner AM, Li S, Fathi AT, et al. Haematopoietic cell transplantation with and without sorafenib maintenance for patients with FLT3-ITD acute myeloid leukaemia in first complete remission. $\mathrm{Br} J$ Haematol. 2016;175(3):496-504.

8. Battipaglia G, Ruggeri A, Massoud R, et al. Efficacy and feasibility of sorafenib as a maintenance agent after allogeneic hematopoietic stem cell transplantation for Fms-like tyrosine kinase 3-mutated acute myeloid leukemia. Cancer. 2017;123(15):2867-2874.

9. Ravandi F, Alattar ML, Grunwald MR, et al. Phase 2 study of azacytidine plus sorafenib in patients with acute myeloid leukemia and FLT-3 internal tandem duplication mutation. Blood. 2013;121(23):4655-4662.

10. Antar A, Kharfan-Dabaja MA, Mahfouz R, Bazarbachi A. Sorafenib Maintenance Appears Safe and Improves Clinical Outcomes in FLT3ITD Acute Myeloid Leukemia After Allogeneic Hematopoietic Cell Transplantation. Clin Lymphoma Myeloma Leuk. 2015;15(5):298302.

11. Metzelder SK, Schroeder T, Lubbert M, et al. Long-term survival of sorafenib-treated FLT3-ITD-positive acute myeloid leukaemia patients relapsing after allogeneic stem cell transplantation. Eur J Cancer. 2017;86:233-239.

12. Winkler J, Rech D, Kallert S, et al. Sorafenib induces sustained molecular remission in FLT3-ITD positive AML with relapse after second allogeneic stem cell transplantation without exacerbation of acute GVHD: a case report. Leuk Res. 2010;34(10):e270-272.

13. Sharma M, Ravandi F, Bayraktar UD, et al. Treatment of FLT3-ITDpositive acute myeloid leukemia relapsing after allogeneic stem cell transplantation with sorafenib. Biol Blood Marrow Transplant. 2011;17(12):1874-1877.

14. Schmid C, Labopin M, Nagler A, et al. Donor lymphocyte infusion in the treatment of first hematological relapse after allogeneic stemcell transplantation in adults with acute myeloid leukemia: a retrospective risk factors analysis and comparison with other strategies by the EBMT Acute Leukemia Working Party. J Clin Oncol. 2007;25(31):4938-4945

15. Mathew NR, Baumgartner F, Braun L, et al. Sorafenib promotes graftversus-leukemia activity in mice and humans through IL-15 production in FLT3-ITD-mutant leukemia cells. Nat Med. 2018;24(3):282291. 